\title{
Temperature Change and Its Elevation Dependency in the Source Region of the Yangtze River and Yellow River
}

\author{
Chongyi $\mathrm{E}^{1,2}$, Hongchang $\mathrm{Hu}^{3}$, Hong $\mathrm{Xie}^{4} \&$ Yongjuan $\mathrm{Sun}^{2}$ \\ ${ }^{1}$ Key Laboratory of Qinghai-Tibetan Plateau Environment and Resource, MOE, Qinghai Normal University, \\ Xining 810000, China \\ ${ }^{2}$ Qinghai Institute of Salt Lakes, Chinese Academy of Sciences, Xining 810008, China \\ ${ }^{3}$ Department of Hydraulic Engineering, Tsinghua University, Beijing, 100084, China \\ ${ }^{4}$ Lanzhou Institute of Seismology, China Earthquake Administration, Lanzhou 730000, China \\ Correspondence: Chongyi E, Key Laboratory of Qinghai-Tibetan Plateau Environment and Resource, MOE, \\ Qinghai Normal University, Xining 810000, China. E-mail: echongyi@163.com
}

Received: March 6, 2014 Accepted: March 24, 2014 Online Published: May 3, 2014

doi:10.5539/jgg.v6n2p124 URL: http://dx.doi.org/10.5539/jgg.v6n2p124

\begin{abstract}
The study of temperature change and its elevation dependency in the source region of the Yangtze River and Yellow River have been insufficient owing to the lack of adequate observation stations and long-term climatic data. In this study five temperature indices of 32 stations from 1961 to 2007 in and near the source region are used. The 32 stations all have experienced significant warming; the warming amplitudes are higher than the mean warming amplitude of the Qinghai-Tibetan plateau. The warming amplitudes and the numbers of stations showing significant warming trends in mean minimum temperature and extreme minimum temperature are higher than that of the mean maximum temperature and extreme maximum temperature. The elevation dependency of climatic warming and the amount of significant warming stations are not obvious; the influence of human activity and urbanization may be higher. The warming amplitudes of 26 stations above $3000 \mathrm{~m}$ tend to be uniform, and there is no significant law at 6 stations below $3000 \mathrm{~m}$. On the contrary, the ratio of stations showing significant warming in minimum temperature above $4000 \mathrm{~m}$ is far less than that of the stations below $4000 \mathrm{~m}$.
\end{abstract}

Keywords: warming amplitude, significant level, elevation dependency, the source region of the Yangtze River and Yellow River, global warming

\section{Introduction}

Regional climate change is significant to study the origin of climate and the effects of regional climate change on ecosystem and social-economical system. With the global warming, the regional climate change will influence the human activities and ecosystem, also, these feed back to the global warming. As regional climate varies in the space, many studies had proved a relationship between the warming trend and elevation. Using experimental data, such as meteorological and ice core data, researches in some regions had showed the warming increases as the elevation increases. The warming speed at high elevations was greater than that at low elevations in Alpine mountain areas (Benistion \& Rebetez, 1996); Diaz et al. (1997) found that relationship appears to be more closely regarding to increases in daily minimum temperature than changes in the daily maximum temperature (Diaz \& Bradley, 1997). Some studies in the Qinghai-Tibetan Plateau also showed this relationship: the data of five meteorological stations in Mt. Jolmo-Lungma showed the warming trend is obvious, and the warming amplitude is maximum at Dingri where altitude is the highest (Yang et al., 2006); the ice data in the source region of Yangtze river in Qinghai-Tibetan plateau showed the warming response is more sensitive at high altitudes (Kang et al., 2007); the increase in amplitude of mean temperature increases with the increase of altitude and this trend is verified by the ice data (Liu et al., 2000); the study in Qinghai-Tibetan Plateau also shows there is no warming below $500 \mathrm{~m}$, the increase amplitude from $1500 \mathrm{~m}-2500 \mathrm{~m}$ is about $0.12{ }^{\circ} \mathrm{C} / 10 \mathrm{yr}$ and $0.25^{\circ} \mathrm{C} / 10 \mathrm{yr}$ above $3500 \mathrm{~m}$, the result shows the response to global climate change at high altitudes is more sensitive (Yao et al., 2000).

Experimental data are important to study the relationship between warming trend and elevation. However, the 
climate model provides another possible way to assess the elevation dependency on longer time scales against independent proxy records. A nested regional climate model shows the elevation dependency, and the model also showed that the warming was more pronounced at high elevation compare to that at low elevation in winter and spring (Giorgi et al., 1997); according to the study of the climatic model, it is the snow surface reactions due to the increase of the snowline, the surface temperature increased obviously at high elevations (Fyfe et al., 1999).

However, enhanced warming with the increase of elevation in some regions showed contrasting patterns: lower elevation at the west of the Andes have experienced the greatest warming, while the warming is moderate at high elevations in the east (Vuille et al., 2003); the temperature ascending rate of surface temperature is less at the high altitude of the Qinghai-Tibetan plateau ( $\mathrm{Li}$ et al., 2005); and the study also shows there is no remarkable correlation between the temperature extremes and the elevation on the Tibetan Plateau (You et al., 2008).

Rivers, lakes, glaciers and jokuls are widely distributed at the source region of Yangtze River and Yellow River. It's the most important and extensive ecological function zone in China and it is called the Chinese Water Tower. It located in the hinterland of the Qinghai-Tibetan plateau, which is the driver and amplifier of the Global Climatic Change (Pan \& Li, 1996), and its thermal action is important to the climate of China even the world (Gao et al., 2003). With the background of global climatic change, the study of climatic change in the source region of the Yangtze River and Yellow River is very significant to the ecosystem and water resource security in this region. Some studies show the warming is obvious in the last 40 years on Qinghai-Tibetan plateau; whereas, there is still a controversy regarding the elevation dependency of temperature variation and significant level. Based on the 5 temperature indices over 47 years at the 32 weather stations in the source region of Yangtze River and Yellow River which are located in the hinterland of Qinghai-Tibetan Plateau, the study investigate the warming trend and analyze their elevation dependency.

\section{Study Area and Data}

The source region of the Yangtze River and Yellow River is located in the hinterland of the Qinghai-Tibetan plateau, and belongs to the Naqu-Guoluo subhumid and QiangTang semiarid area. The entire study area is in the Qinghai-Tibetan plateau subfrigid zone with the mean elevation about $3900 \mathrm{~m}$. It is the main water source reserve and runoff-generation area of the Yangtze River and Yellow River, and is the key source region that maintains the natural ecological security and social economically sustainable development (Wang et al., 2001).

The meteorological data of 32 weather stations in which the time series are relatively complete from year 1961-2007, are provided by the national meteorological center of the China Meteorological Bureau. The weather stations are widely distributed in QingHai, Tibet, SiChuan and GanSu Province. And the elevation extent is from about $2238.1 \mathrm{~m}-4801.0 \mathrm{~m}$ (Figure 1). There are five temperature variables examined with the goal of understanding the temperature change and its elevation dependency which are the mean annual temperature, mean annual maximum temperature, mean annual minimum temperature, extreme maximum temperature and extreme minimum temperature. 


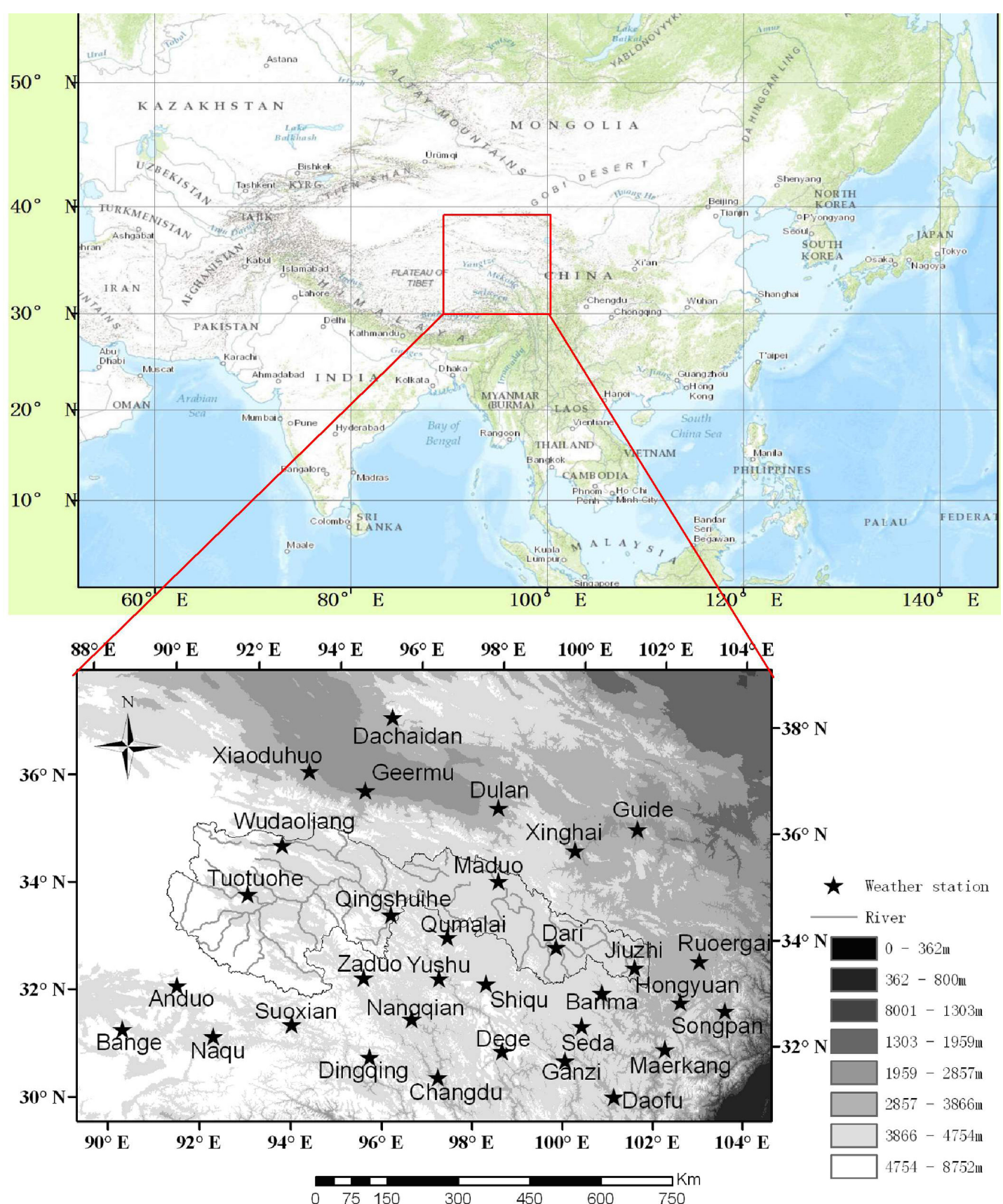

Figure 1. The weather station in and near the study area

\section{Steps and Method}

The systematic approach that was adopted herein to determine the warming trend and its elevation dependency can be summarized in the steps outlined below:

The fist step was to calculate the lag- 1 serial correlation coefficient $\left(r_{1}\right)$ of the sample data; if $r_{1}>0.1$, the data set to be "pre-whitened"; if $r_{1}<0.1$, it keeps invariant.

The second step was to check the presence of trends and significant level in the data set, and this was done using the Mann-Kendall non-parametric test.

The third step was to determine the change in amplitude; and the sen's estimator was used here.

The fourth step was to calculate the elevation dependency of the warming trend; the linear parametric test and the coefficient of variation were used here, $\beta_{\text {alt }}$ was used to repress the warming amplitude with the elevation. The steps outlined above are described in the sections that follow: 


\section{Pre-whitened}

A positive serial correlation in the sample data, the non-parametric will suggest a significant trend which is actually random more often than specified by the significance level, the data set to be "pre-whitened" to eliminate the effect of serial correlation before applying the Mann-Kendall test. If $r_{1}<0.1$, the Mann-Kendall test is applied to original values of the data set; if $r_{1}>0.1$, the "pre-whitened" data set $\left(Y_{t}\right)$ may be obtained as follows (Sheng \& Wang, 2002):

$$
Y_{t}=X_{t}-r_{1} X_{t-1}
$$

The lag-1 serial correlation coefficient $\left(r_{1}\right)$ will be calculated as follows:

$$
\begin{gathered}
r_{1}=\frac{(1 /(n-1)) \sum_{t=1}^{n-1}\left[X_{t}-E(X)\right]\left[X_{t+1}-E(X)\right]}{(1 / n) \sum_{t=1}^{n}\left[X_{t}-E(X)\right]^{2}} \\
\mathrm{E}(\mathrm{X})=\frac{1}{\mathrm{n}} \sum_{t=1}^{n} X_{t}
\end{gathered}
$$

\section{Mann-Kendall trend test}

The Mann-Kendall test is a non-parametric test and has been widely used to test for randomness against trends in hydrology and climatology (Xu et al., 2003; Jin et al., 2003).

$$
\begin{gathered}
Z= \begin{cases}\frac{S-1}{\sqrt{V(S)}} & S>0 \\
0 & S=0 \\
\frac{S-1}{\sqrt{V(S)}} & S<0\end{cases} \\
S=\sum_{i=1}^{n-1} \sum_{j=i+1}^{n} \operatorname{sgn}\left(X_{j}-X_{i}\right) \\
\operatorname{sgn}=\left\{\begin{array}{ccc}
1 & \text { if } & \theta>0 \\
0 & \text { if } & \theta=0 \\
-1 & \text { if } & \theta<0
\end{array}\right.
\end{gathered}
$$

For independent, identically distributed random variables with no tied data values

$$
V(S)=\frac{n(n-1)(2 n+5)}{18}
$$

When some data values are tied, the correction to $V(S)$ is

$$
\begin{gathered}
V(S)=\frac{n(n-1)(2 n+5)-\sum_{i=1}^{n} t_{i} i(i-1)(2 i+5)}{18} \\
P=\frac{1}{\sqrt{2 \pi}} \int_{-\infty}^{Z} e^{-t^{2} / 2} d t
\end{gathered}
$$

\section{Sen's estimator}

The non-parametric robust estimate of the magnitude of the slope $\beta$ (Xu et al., 2003),

$$
\beta=\operatorname{Median}\left(\frac{X_{j}-X_{i}}{j-i}\right) \quad j>i
$$




\section{Result and Discussion}

\subsection{The Temperature Change in the Last 47 (1961-2007) Years}

The elevation and the warming amplitude of each station are shown in the Figure 2. The change trend of five temperature indices at 32 stations in and near the source region all exceed 0 , and show the warming trend in all the stations. There is a uniform warming trend in the source region. The warming amplitude of annual mean temperature is about $0.32{ }^{\circ} \mathrm{C} / 10 \mathrm{yr}$, and it exceeds the warming amplitude of annual mean temperature $0.16^{\circ} \mathrm{C} / 10 \mathrm{yr}$ which studied by Liu et al. (2000) and $0.26^{\circ} \mathrm{C} / 10 \mathrm{yr}$ studied by $\mathrm{Du}(2001)$ on the Qinghai-Tibetan plateau. The source region is the most sensitive region to global warming on the whole Qinghai-Tibetan plateau. The warming trend of annual mean maximum temperature, annual mean annual minimum temperature, annual extreme maximum temperature and annual extreme minimum temperature are $0.233{ }^{\circ} \mathrm{C} / 10 \mathrm{yr}, 0.426{ }^{\circ} \mathrm{C} / 10 \mathrm{yr}$, $0.308{ }^{\circ} \mathrm{C} / 10 \mathrm{yr}$ and $0.739{ }^{\circ} \mathrm{C} / 10 \mathrm{yr}$, respectively. The value of warming amplitude in annual mean minimum temperature and extreme minimum temperature is the greatest, and the result is consistent with the whole Qinghai-Tibetan plateau (Figure 2).

The warming trend in annual mean temperature is observed at $93.75 \%$ and $100 \%$ of stations at level of 0.05 and 0.1 respectively. There is a significant warming trend in annual mean temperature across the whole source region, and the level is also higher than the whole Qinghai-Tibetan plateau (Table 1). The ratios and numbers of the warming stations with mean annual minimum temperature and extreme minimum temperature at the significant level of 0.05 and 0.1 are higher than the level of the mean annual maximum temperature and extreme maximum temperature, but it is consistent with the warming amplitude too (Figure 3).

The source region is located in the hinterland of Qinghai-Tibetan plateau, the glacier, wetland and water system are widely distributed here, and it is extremely susceptible to the global warming trend, and the warming amplitude and the significant warming stations are much higher than the entire Qinghai-Tibetan plateau. According to five temperature indices: there is an obvious increase of the warming amplitude and the number of warming significant stations in annual mean temperature, annual mean minimum temperature and extreme minimum.

Table 1. The number and proportion of station which the warming is significant at the confidence of 0.05 and 0.1

\begin{tabular}{lcccccc}
\hline & $\begin{array}{c}\text { Confidence } \\
\text { level }\end{array}$ & $\begin{array}{c}\text { Annual } \\
\text { mean } \\
\text { temperature }\end{array}$ & $\begin{array}{c}\text { Annual } \\
\text { maximum } \\
\text { temperature }\end{array}$ & $\begin{array}{c}\text { Annual } \\
\text { minimum } \\
\text { temperature }\end{array}$ & $\begin{array}{c}\text { Extreme } \\
\text { maximum } \\
\text { temperature }\end{array}$ & $\begin{array}{c}\text { Extreme } \\
\text { minimum } \\
\text { temperature }\end{array}$ \\
\hline $\begin{array}{l}\text { Station } \\
\text { number }\end{array}$ & 0.05 & 30 & 17 & 29 & 18 & 25 \\
$\begin{array}{l}\text { Station } \\
\text { proportion } \\
(\%)\end{array}$ & 93.75 & 53.125 & 90.625 & 56.25 & 78.125 \\
\hline $\begin{array}{l}\text { Station } \\
\text { number }\end{array}$ & 0.1 & 32 & 24 & 31 & 22 & 27 \\
$\begin{array}{l}\text { Station } \\
\text { proportion } \\
(\%)\end{array}$ & 100 & 75 & 96.875 & 68.75 & 84.375 \\
\hline
\end{tabular}

Table 2. The elevations depency of warming at 26 stations above $3000 \mathrm{~m}$

\begin{tabular}{lllllll}
\hline & & $\begin{array}{l}\text { Annual } \\
\text { mean } \\
\text { temperature }\end{array}$ & $\begin{array}{l}\text { Annual } \\
\text { maximum } \\
\text { temperature }\end{array}$ & $\begin{array}{l}\text { Annual } \\
\text { minimum } \\
\text { temperature }\end{array}$ & $\begin{array}{l}\text { Extreme } \\
\text { Maximum } \\
\text { temperature }\end{array}$ & $\begin{array}{l}\text { Extreme } \\
\text { minimum } \\
\text { temperature }\end{array}$ \\
\hline $\begin{array}{l}\text { Linear } \\
\text { test }\end{array}$ & $\begin{array}{l}\mathrm{P} \\
\beta_{\text {alt }}\end{array}$ & 0.559 & 0.700 & 0.595 & 0.625 & 0.829 \\
& 0.020 & 0.015 & 0.033 & 0.034 & 0.036 \\
\hline \multicolumn{2}{c}{$\begin{array}{l}\text { coefficient } \\
\text { of variation }\end{array}$} & 0.268 & 0.450 & 0.372 & 0.580 & 0.564 \\
\hline Mean warming $\left({ }^{\circ} \mathrm{C} / 10 \mathrm{yr}\right)$ & 0.312 & 0.218 & 0.415 & 0.294 & 0.723 \\
\hline
\end{tabular}



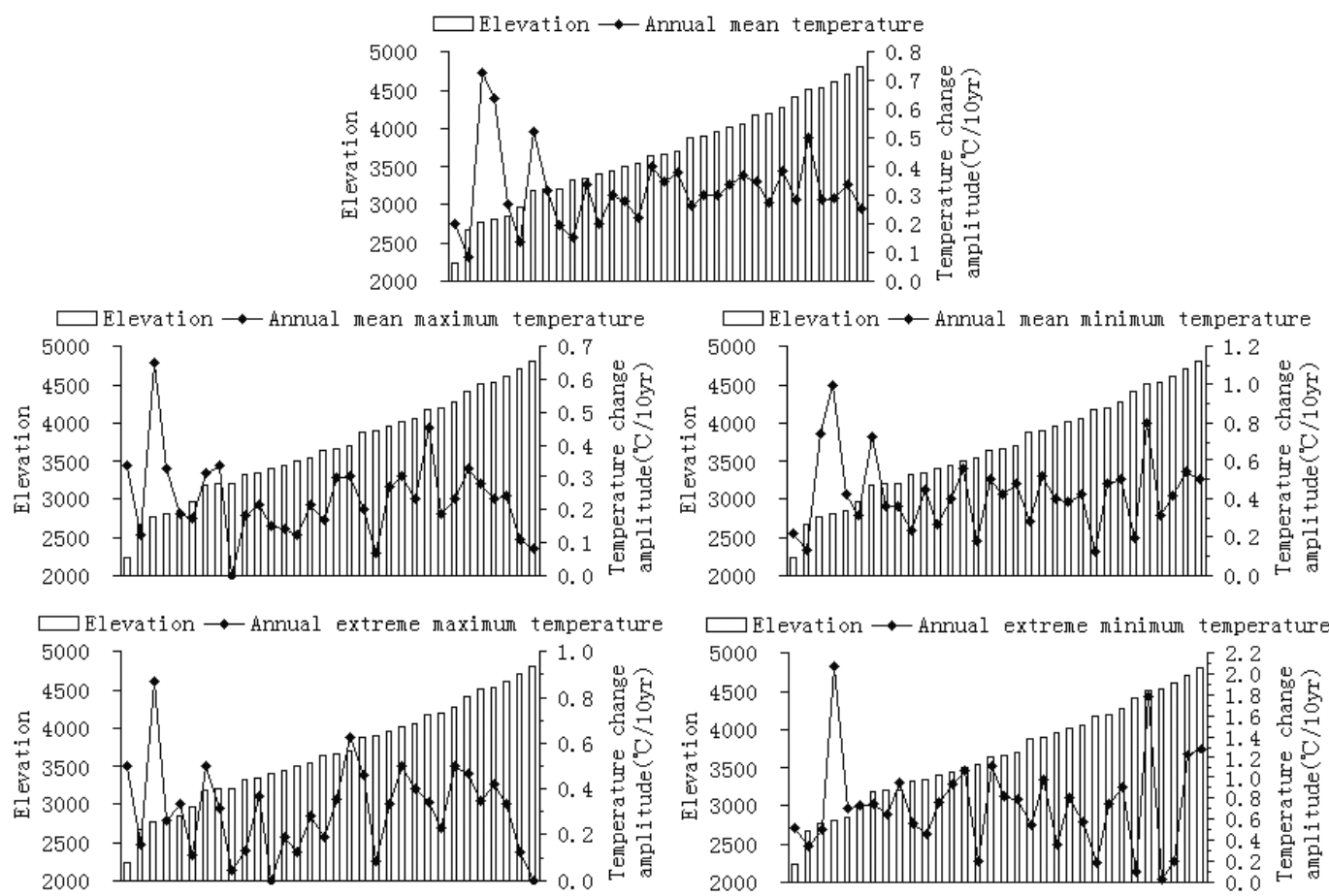

Figure 2. The temperate change amplitude of five temperature indices
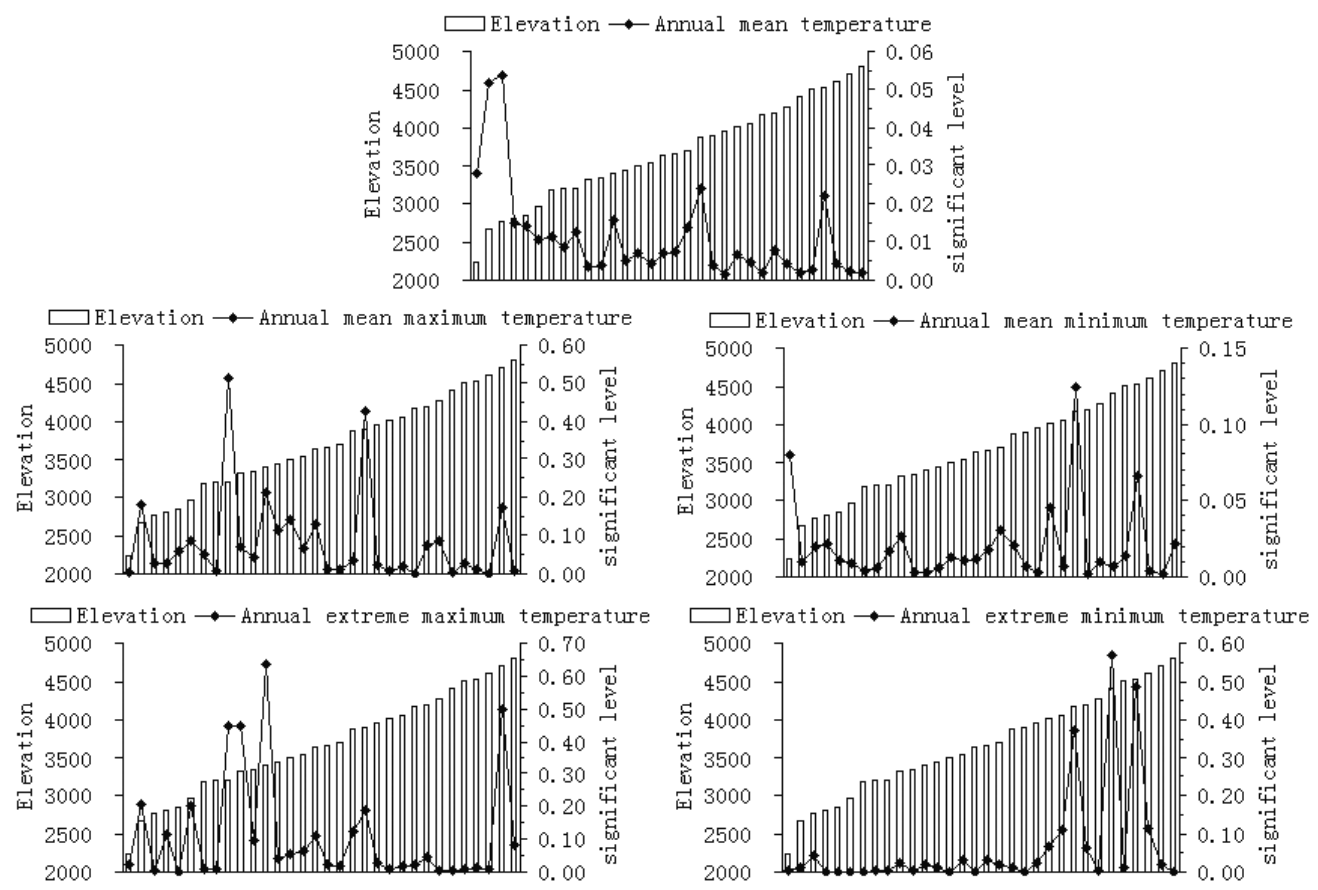

Figure 3. The warming significant level of five temperature indices

\subsection{The Elevation Dependency of Temperature Change}

With the global warming, the regional temperature changes at different elevations showing different characteristics and their elevation dependency are widely disputed. The study of the warming trend of elevation dependency is relatively weak and the conclusions are different because of the scarce of the weather stations and the integrity of the data set on the Qinghai-Tibetan Plateau. In our study, there are 32 stations, the 6 of which are at $2000 \mathrm{~m} \sim 3000 \mathrm{~m}$, the other 26 stations are at $3000 \mathrm{~m} \sim 5000 \mathrm{~m}$. The warming amplitude at 6 stations at 2000 
$\mathrm{m} \sim 3000 \mathrm{~m}$ have no significant changes with the elevation, while the influence of human activity is more obvious at the region of $2000 \mathrm{~m} \sim 3000 \mathrm{~m}$. The study by You et al. (2008) also shows the effect of urbanization to warming is higher than the elevation dependency. The elevation dependency of warming amplitude of five temperature indices are studied by the linear parametric test, the results show that the confidence level is not significant, and also, the change trend is not significant. The coefficients of variation of five temperature indices are $0.268,0.450$, $0.370,0.580$, and 0.564 respectively. The discrete degree of annual mean temperature is least, the discrete degree of annual mean minimum temperature and annual extreme minimum temperature is less than that of annual mean maximum temperature and annual extreme maximum (Table 2). The warming amplitude of the five temperature indices at the different stations of $3000 \mathrm{~m} \sim 5000 \mathrm{~m}$ is well coincident, and there is no significant elevation dependency between altitude and temperature change.

The elevation dependency of warming significant stations of five temperature indices is not obvious. Most stations above $4000 \mathrm{~m}$ show an unobvious warming trend $(\mathrm{P}>0.05)$ in extreme minimum temperature. There are 11 stations above $4000 \mathrm{~m}$, of which only 4 stations show a significant increasing trend in extreme minimum temperature while the other 21 stations below $4000 \mathrm{~m}$ all show a significant increasing trend.

\section{Conclusion}

The regional warming is significant and extensive in and near the source region of the Yangtze River and Yellow River, the significant warming of the annual mean temperature at the 32 stations at the confidence level of 0.05 and 0.1 are $93.75 \%$ and $100 \%$ respectively, and the warming amplitude is $0.318{ }^{\circ} \mathrm{C} / 10 \mathrm{yr}$, and it is higher than the mean temperature of the whole Qinghai-Tibetan plateau; the warming amplitude and the number of warming significant stations of annual mean minimum temperature and annual extreme minimum temperature at the confidence of 0.05 and 0.1 are higher than the annual mean maximum temperature and annual extreme maximum temperature.

The warming of 6 stations below $3000 \mathrm{~m}$ has no significant change. The warming amplitude of 26 stations above $3000 \mathrm{~m}$ is coincident, and the elevation dependency of warming amplitude is not obvious. The study of warming significant stations also show that there is no remarkable relationship between elevation and the significance level of warming. The proportion of stations showing warming significant trend in extreme minimum temperature above $4000 \mathrm{~m}$ less than that below $4000 \mathrm{~m}$.

\section{Acknowledgements}

This study was supported by a China NSF grant (41361047), Qinghai Normal University Creative Fund, Natural Science Funds of Qinghai Province (2011-Z-926Q). Finally, the authors' special thanks go to Editor and referees of this paper whose valuable comments and great help in sharpening the writing led to substantial improvement of this paper.

\section{References}

Beniston, M., \& Rebetez, M. (1996). Regional behavior of minimum temperatures in Switzerland for the period 1979-1993. Theoretical and Applied Climatology, 53(4), 231-243. http://dx.doi.org/10.1007/BF00871739

Diaz, H. F., \& Bradley, R. S. (1997). Temperature variations during the last century at high elevation sites. In Climatic Change at High Elevation Sites (pp. 21-47). Springer Netherlands. http://dx.doi.org/10.1007/978-94-015-8905-5_2

Du, J. (2001). Change of Temperature in Tibetanan Plateau From 1961 to 2000. Acta Geographica Sinica, 56, 682-690.

Fyfe, J. C., \& Flato, G. M. (1999). Enhanced climate change and its detection over the Rocky Mountains. Journal of Climate, 12(1), 230-243. http://dx.doi.org/10.1175/1520-0442-12.1.230

Gao, R., Wei, Z. G., Dong, W. J., Wang, C. H., \& Zhong, H. L. (2003). Variation of the snow and frozen soil over Qinghai-Xizang Plateau in the late twentieth century and their relations to climatic change. Plateau Meteorology, 22(2), 191-196.

Giorgi, F., Hurrell, J. W., Marinucci, M. R., \& Beniston, M. (1997). Elevation dependency of the surface climate change signal: A model study. Journal of Climate, 10(2), 288-296. http://dx.doi.org/10.1175/1520-0442(1997)010<0288:EDOTSC >2.0.CO;2

Kang, S., Zhang, Y., Qin, D., Ren, J., Zhang, Q., Grigholm, B., \& Mayewski, P. A. (2007). Recent temperature increase recorded in an ice core in the source region of Yangtze River. Chinese Science Bulletin, 52(6), 825-831. http://dx.doi.org/10.1007/s11434-007-0140-1 
Li, D. L., Zhong, H. L., Wu, Q. B., Zhang, Y. J., Hou, Y. L., \& Tang, M. C. (2005). Analyses on changes of surface temperature over Qinghai-Xizang Plateau. Plateau Meteorology, 3, 001.

Liu X. D., \& Chen, B. D. (2000). Climatic warming in the Tibetan plateau during recent years. International $\begin{array}{llll}\text { Journal of Climatology, } & 20, & 1729-1742 .\end{array}$ http://dx.doi.org/10.1002/1097-0088(20001130)20:14<1729::AID-JOC556>3.0.CO;2-Y

Pan, B. T., \& Li, J. J. (1996). Qinghai-Tibetanan Plateau: A Driver and Amplifier of the Global Climatic Change III. The effects of the uplift of Qinghai-Tibetanan Plateau on Climatic Changes. Journal of Lanzhou University (Natural Sciences), 32, 108-115.

Vuille, M., Bradley, R. S., Werner, M., \& Keimig, F. (2003). 20th century climate change in the tropical Andes: observations and model results. In Climate Variability and Change in High Elevation Regions: Past, Present \& Future (pp. 75-99). Springer Netherlands.

Wang, G., Cheng, G., \& Shen, Y. (2001). Study on the eco-environment in headwater regions and their comprehensive protection. Lanzhou: Lanzhou University Press.

Xu, Z. X., Takeuchi, K., \& Ishidaira, H. (2003). Monotonic trend and step changes in Japanese precipitation. Journal of Hydrology, 279(1), 144-150. http://dx.doi.org/10.1016/S0022-1694(03)00178-1

Yang, X., Zhang, Y., Zhang, W., Yan, Y. P., Wang, Z. F., Ding, M. J., \& Chu, D. (2006). Climate change in Mt. Qomolangma region in China during the last 34 years. Acta Geographica Sinica-Chinese Edition, 61(7), 696.

Yao, T. D., Liu, X. D., \& Wang, N. L. (2000). Amplitude of climatic changes in Qinghai-Tibetanan Plateau. Chinese Science Bulletin, 45, 1236-1243. http://dx.doi.org/10.1007/BF02886087

You, Q., Kang, S., Pepin, N., \& Yan, Y. (2008). Relationship between trends in temperature extremes and elevation in the eastern and central Tibetan Plateau, 1961-2005. Geophysical Research Letters, 35(4). http://dx.doi.org/10.1029/2007GL032669

Yue, S., \& Wang, C. Y. (2002). Applicability of prewhitening to eliminate the influence of serial correlation on the Mann-Kendall test. Water Resources Research, 38(6), 4-1-4-7. http://dx.doi.org/10.1029/2001WR000861

\section{Copyrights}

Copyright for this article is retained by the author(s), with first publication rights granted to the journal.

This is an open-access article distributed under the terms and conditions of the Creative Commons Attribution license (http://creativecommons.org/licenses/by/3.0/). 